SPOTLIGHT ON CANADA

\title{
Bringing science to market
}

\section{Commercialization programs help Canadian researchers see the results of their work take flight}

\section{"What's missing here}

\section{isn't the science, it's}

\section{the entrepreneurs."}

Abby Goodrum, vice president for research at Wilfrid Laurier University in Waterloo
When University of Toronto scientist Stewart Aitchison and his PhD student James Dou developed a portable, hand-held device that analyses $\mathrm{CD}^{+} \mathrm{T}$ cell levels from a single drop of blood, they knew their 'laboratory on a chip' had the potential to improve public health. $\mathrm{CD}^{+} \mathrm{T}$ cells are the immune cells destroyed during HIV infections, and their concentration is a measure of how urgently an HIV patient needs treatment.

Aitchison and Dou wanted to see their innovation put into practice, so they initiated a technology transfer process with the university and founded start-up company ChipCare in 2009. Dou is now Chief Technical Officer, and in 2013 the company recruited James Fraser - a former Médecins Sans Frontières doctor and co-founder of the medical organisation Dignitas International - as its CEO. The inventors are preparing their device, now at the prototype stage, for HIV testing in developing countries, and

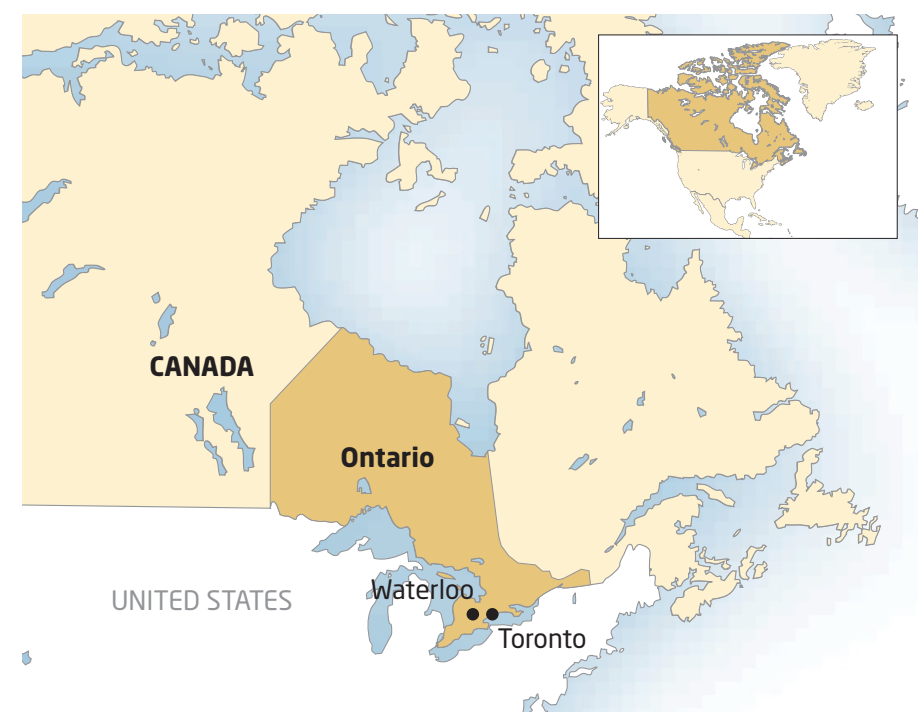

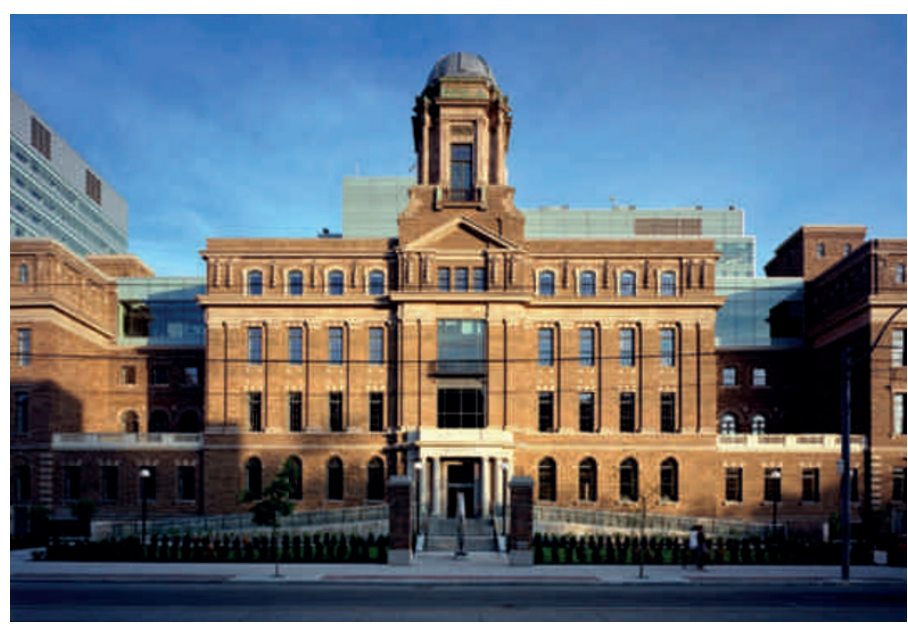

The MARS heritage building, home to MARS Innovation and its sister organization MARS Discovery District.

adapting it to detect other diseases, such as malaria and tuberculosis.

This entrepreneurial story is one of many emerging across Canada, and especially in Ontario province. "There is lots of untapped potentially commercializable research here," says Benjamin Neel, director of the Ontario Cancer Institute, the research arm of the Princess Margaret Cancer Centre in Toronto. The challenge is how to bring that research out of the lab and onto the market place.

Over the last few years initiatives and organisations have been set up to help scientists to do just that, and the payoff is already becoming evident. Neel says his institute, which aims to improve patient care, has several products - from an RNAi delivery platform to lung-cancer diagnostic tools being translated from research to the commercial sphere.

Industry leaders acknowledge that many scientists lack the expertise and guidance to turn an idea into a business. "What's missing here isn't the science, it's the entrepreneurs," says Abby Goodrum, vice president for research at Wilfrid Laurier University in Waterloo. Goodrum says that when staff at Wilfrid Laurier canvassed leaders of the technology sector in Canada, they consistently spoke highly of the innovation pipeline and praised the creative talent, but acknowledged a lack of business acumen. In response, the university has developed a highly applied business school, with around 600 students from business and nonbusiness streams currently enrolled in entrepreneurship courses. "We have entrepreneurship across the curriculum," says Goodrum. "It helps students prepare for when they may start their own company from the innovations that are coming out of their own research."

For those students who are ready to make the leap from the classroom to real business 


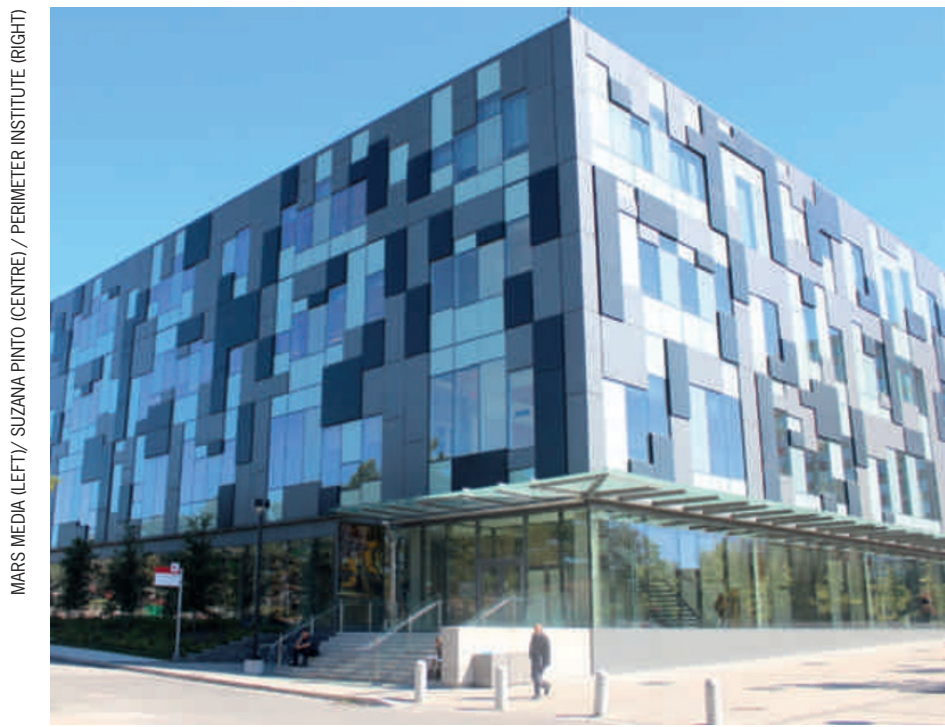

The new Life Sciences building at the University of York in Toronto should yield new innovations.

experience, the university offers the Laurier Launchpad, which mentors students through the process of launching their own company. Since the scheme started in 2011, 62 groups - around 170 students - have been accepted into the programme and 28 start-ups have been founded. From the Launchpad, start-up companies can progress to the Accelerator Centre, a joint enterprise with the University of Waterloo, where the students can access further expertise, capital and business networks.

\section{Guiding light}

Letting individuals take the lead, or guiding those who are interested, are also strategies at York University in Toronto. "Some academics want to be completely independent, others want lots of help," says Margaret Hough, director of research and international relations in the Faculty of Science.

Hough is hoping that many marketable developments will spring from the university's new Life Sciences building, which opened in 2012, funded by $\$ 70$ million each from the federal and Ontario provincial governments and $\$ 15$ million of private funds. The building has two floors dedicated to undergraduate teaching, and two for research laboratories, a layout that Hough says gives students much more exposure to research. The laboratories are stocked with $\$ 5$ million worth of equipment, and there is a strong focus on interdisciplinary collaboration, as the kit is shared by researchers across the chemistry, biology and engineering departments and is also used by scientists outside the university.

Collaborations between disciplines and between institutes are increasingly common in the drive for innovative research, says Alan Bernstein, CEO of the Canadian Institute for Advanced Research (CIFAR) which brings together nearly 400 researchers from 16 countries in long-term, multi-disciplinary projects. CIFAR's mission is to create knowledge that "enriches human life.” Bernstein says there is a growing recognition that breakthroughs that lead to useful applications occur when disciplines interact (see 'Sensory spin-out'), and the organization has built on that approach. For example, the institute's Child and Brain Development group, one of nine current research programs, is jointly led by a fruit-fly geneticist and a paediatrician, and includes social-science researchers.

Bernstein says the Canadian government has recognized the need to integrate research with commercial strategies, and in 2007 set up the Centres of Excellence for Commercialization and Research (CECR) programme. The programme funds 21 CECRs with the mandate to match clusters of research expertise with the opportunities in business.

One of these centres of excellence is MARS (Medical and Related Science) Innovation, which acts as the commercialization office for four universities, nine teaching hospitals and two research institutes, all in Ontario. MARS Innovation and its sister organization MARS Discovery District are not-for-profit organizations that are tightly integrated in Canadian research commercialization. They are based in a heritage building that once belonged to the Toronto University Hospital, in the heart of the city's 'discovery district' - the inner-city conglomeration of universities, institutes and hospitals which has a reputation as a research hotbed. "Here, all the different actors in the commercialization sphere come together in one space," says Ilse Treurnicht, CEO of MARS Discovery District.

MARS Innovation has seen around 1000 intellectual-property disclosures from its member

\section{Sensory spin-out}

The superiority of humans over computers when it comes to recognizing objects or sounds is being explored by researchers at the Canadian Institute for Advanced Research (CIFAR) who want to develop computer algorithms to mimic the accuracy of our complex sensory systems.

The Neural Computation and Adaptive Perception Program, which has members from the provinces of British Columbia, Ontario and Quebec, as well as from the US, Finland, Israel and the UK, wants to know how the human brain converts sensory stimuli into information and to recreate human-style learning in computers. Their research focuses on an artificial-intelligence technique called 'deep neural networks' to 'train' computers to recognize patterns, such as objects or a person's voice. Deep neural network concepts are practiced by companies including IBM, Microsoft and Google, and are dramatically reducing software error rates in applications from search engines to interactive voice programs.

University of Toronto scientist Geoffrey Hinton, who leads the CIFAR neural computation program, is a pioneer of the research. Together with students Alex Krizhevsky and Ilya Sutskever, he founded the start-up company DNNresearch, which was bought by Google in March 2013.

Hinton is now employed by both the University of Toronto and Google's California offices, and Krizhevsky and Sutskever are also Google employees.

"They weren't trying to do this to help Google, they were trying to understand the brain," says Alan Bernstein, CIFAR's CEO. But he points to DNNresearch as a beacon of scientific potential when research is properly commercialized. "The CIFAR program created a community of researchers who could push the development of deep learning ahead father and faster than any of us could have done on our own," Hinton says.

\section{Izaak Walton Killam Postdoctoral Fellowships}

Izaak Walton Killam Postdoctoral Fellowships (KPDF) in most fields of study are tenable for up to two years at Dalhousie University, located in Halifax, Nova Scotia, Canada. KPDFs are valued at $\$ 44,000$ CDN per year plus travel allowance, a one-time $\$ 3,000$ research grant, and a $\$ 1,000$ conference travel grant. Applicants must have recently completed a PhD (Jan 2012 or later) at a recognised university and have no current affiliation with Dalhousie University. Applications must be submitted no later than 16-Dec-13. Full details available at:

dal.ca/kpdf

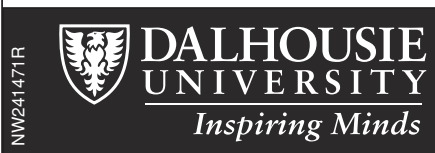




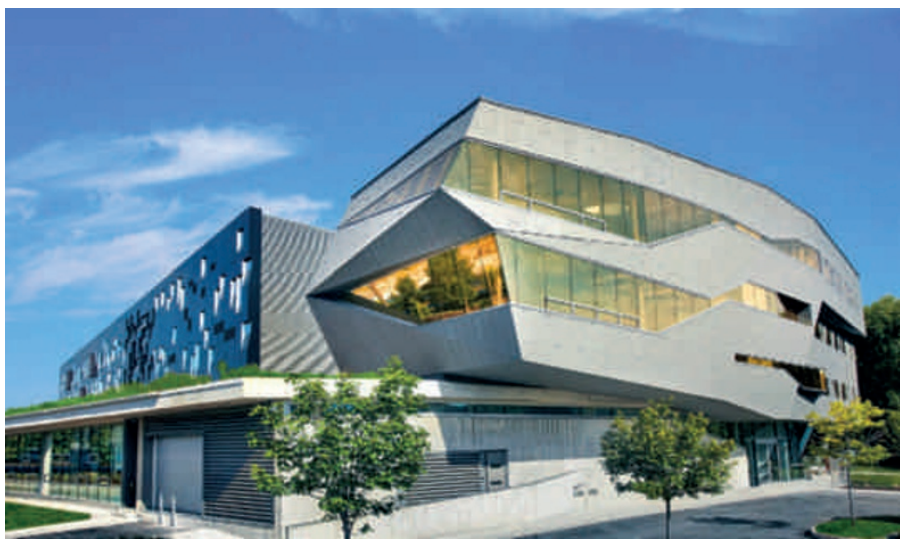

The Perimeter Institute for Theoretical Physics in Waterloo, Ontario.

organizations in the past five years. In a pipeline that Treurnicht describes as "a unique model in Canada," those that are accepted can then be scaled-up in the MARS Discovery District. Many of those inventions come from the University of Toronto, which ranked ranked third in North America the number of new start-up companies it generated between 2009 and 2011, after
MIT and the University of Utah. "Company creation here has taken on a whole new dimension," says Derek Newton, executive director of the university's Innovations and Partnerships Office. His office manages around 150 invention disclosures each year, of which approximately two thirds have at least one student or post-doc as a co-inventor.

Newton says this success stems from a continuum of entrepreneurial programs across the campus. One of these is UTEST, which awards up to $\$ 30,000$ in start-up money to companies in the very earliest stages of idea germination. This helps companies get off the ground and garner further investment from other sources. After only 12 months, the six companies in the first round of investment had generated almost $\$ 1.5$ million in external funding.

\section{Building on basics}

Supporting this rapid trajectory of entrepreneurial change is the fundamental research that is thriving in Canada. This is perhaps best exemplified at the Perimeter Institute for Theoretical Physics in Waterloo, Ontario. Neil Turok, director of the institute, describes its focus on understanding the universe as "the most pure, abstract, fundamental research you can imagine." The institute was established in 1999, as the vision of Mike Lazaridis, founder and Vice Chairman of BlackBerry, who has invested \$160 million in its creation
- a sum which has been matched over the course of the institute's development by both the Ontario and Canadian governments.

Turok says that the institute attracts the world's best thinkers because of the research freedom and intellectual challenge that it offers. Its allure is also bringing fresh investment and opportunities for commercialization. Lazaridis has extended funding to experimental physics, creating the Institute for Quantum Computing in 2002 and the Mike and Ophelia Lazaridis Quantum-Nano Centre in 2012 - both at the University of Waterloo. He has also invested in the commercialization of quantum science, through the launch of Quantum Valley Investments, in partnership with the research entrepreneur Doug Fregin. "Our philosophy is that real innovation comes from understanding how the universe works," says Turok. "We've shown that if you go after that in a very clear, committed way, then the rest will follow".

Nature editorial staff have no responsibility for content
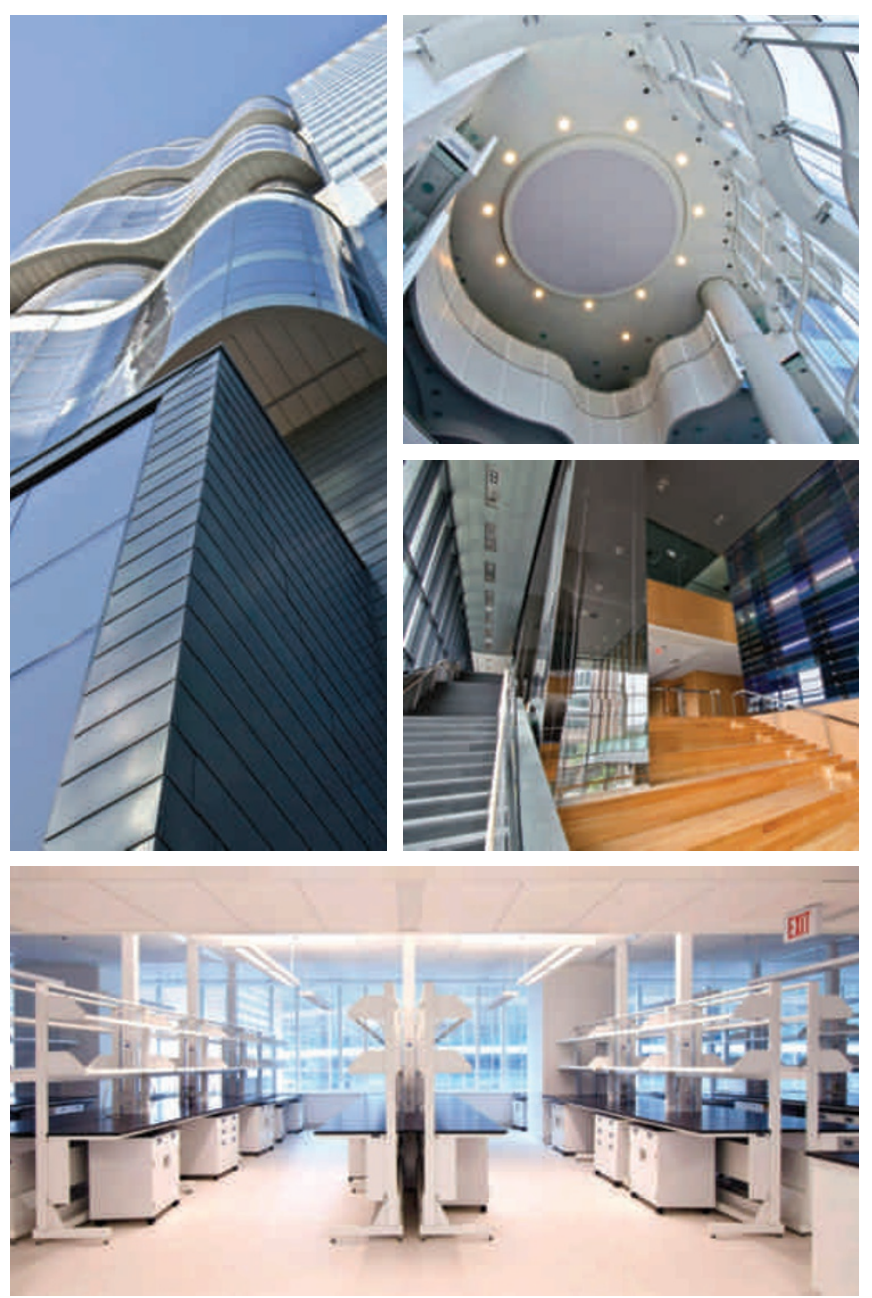

\section{A new era for research at SickKids in Toronto}

In September 2013, SickKids opened the doors to the Peter Gilgan Centre for Research and Learning, bringing together 2,000 researchers, trainees and research staff in a neighbourhood based facility. At the eastern gateway of Toronto's Discovery District, the 21-storeys of research and learning space will spark creativity, drive discovery and fuel innovation, translating research into improved child health worldwide.

Interested in fulfilling our vision Healthier Children. A Better World. visit www.sickkids.ca/research SickKids 


\section{YORK UNIVERSITY}

E stablished in 1965, the Faculty of Science at York University has a long history of academic excellence in delivering interdisciplinary education and acclaimed research in the basic and applied sciences.

Located in north Toronto, the Faculty of Science is neighbour to 900 hightechnology and life sciences companies enabling partnerships for research collaborations and student placement opportunities. The Faculty of Science's central Ontario location provides a prime venue for meeting collaborators from other Ontario universities and international organizations.

Researchers at York have strong international connections with top institutes, universities and organizations. They are at the forefront of global issues, from conservation ecology to modeling in infectious diseases; from regenerating organs using nanomaterials to theoretical cosmology and quantum physics.

The faculty are dedicated leaders in the classroom, taking pride in nurturing and shaping young minds in the undergraduate and graduate science programs. The experiential learning and research

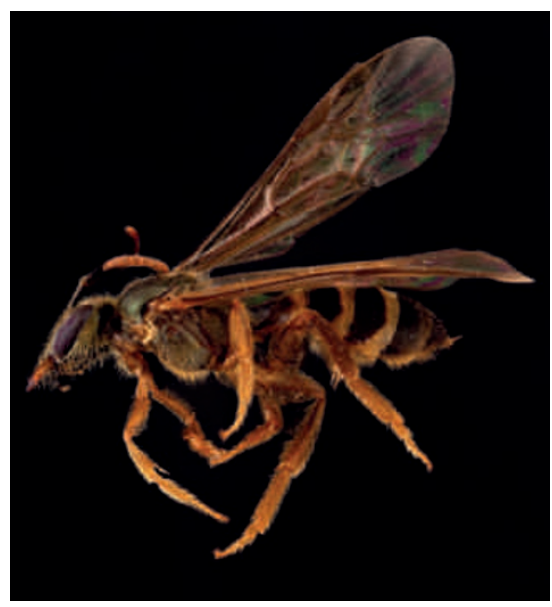

Mexalictus anatolii, the 20,000th bee species, discovered and described by York researcher Sheila Dumesh (under the supervision of Dr. Laurence Packer

environment in the new multi-million dollar Life Science Building gives students the edge they need to flourish and play a key role in the world.

In just under 50 years, the research activities within the Faculty of Science have made great strides with their reach spanning the globe and continuing to cross boundaries. The Faculty of Science's collaborative environment is key to bringing complementary expertise from a range of disciplines to answer local and global problems.

The Faculty of Science sees the importance of further developing environmental biology and ecology, particle physics, life sciences, materials chemistry, mathematics, and statistical sciences. York has acknowledged this and is supporting the expansion of these priority areas by seeking Canada Research Chairs and new faculty positions.

York University's future is bright as we seek a new leader for the Faculty of Science. The new Dean will command a leadership role driving the success of the Faculty and creating new milestones that will have global impact for the next 50 years for science at York.

For more on Bee Taxonomy at York: yorku.ca/bugsrus

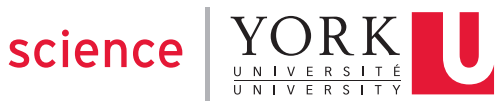

Twitter: @YorkUScience

Website: science.yorku.ca
York University is seeking the next Dean of the Faculty of Science.

York's Faculty of Science enjoys an international reputation for cutting-edge research in areas such as proteomics and genomics, space science, high energy and atomic physics, pure and applied mathematics, and ecology. The Faculty is home to almost 4000 students, 140 faculty members, and 80 staff members in the Departments of Biology, Chemistry, Mathematics \& Statistics, Physics and Astronomy, and Science and Technology Studies, and the Division of Natural Science. It offers an outstanding education in a wide range of basic and applied degree programs in the sciences (BSC,

International BSc, BA, BSc Tech, MSc, and PhD). For more information about York University and the Faculty of Science, please see http://www.yorku.ca.

The Dean is the chief academic and administrative officer of the Faculty, and leads the Faculty in its mission related to teaching, research and scholarship, and service, as well as directing the Faculty's budget, general administration and future development. The appointment is for a five-year term, commencing July 1, 2014. Consideration of candidates will begin in October 2013. Written nominations, applications or expressions of interest for the position should be submitted in confidence to the address shown below. York University is committed to Employment Equity and has implemented a policy of Affirmative Action. All qualified candidates are encouraged to apply; however, Canadian citizens and Permanent Residents will be given priority.

Janet Wright \& Associates Inc

174 Bedford Road, Suite 200

Toronto, ON M5R 2K9

yorkdeanscience@jwasearch.com

\section{The Faculty of Science is seeking} Chairs in:

\section{- Cardiovascular Biology}

- Environmental Biology and Ecology

- Theoretical Particle Physics/Cosmology

FACULTY POSITION

\section{The Faculty of Science is seeking a tenure-track position in:}

\section{- Actuarial Mathematics}

\section{For more information about these and other} opportunities please visit: science.yorku.ca 


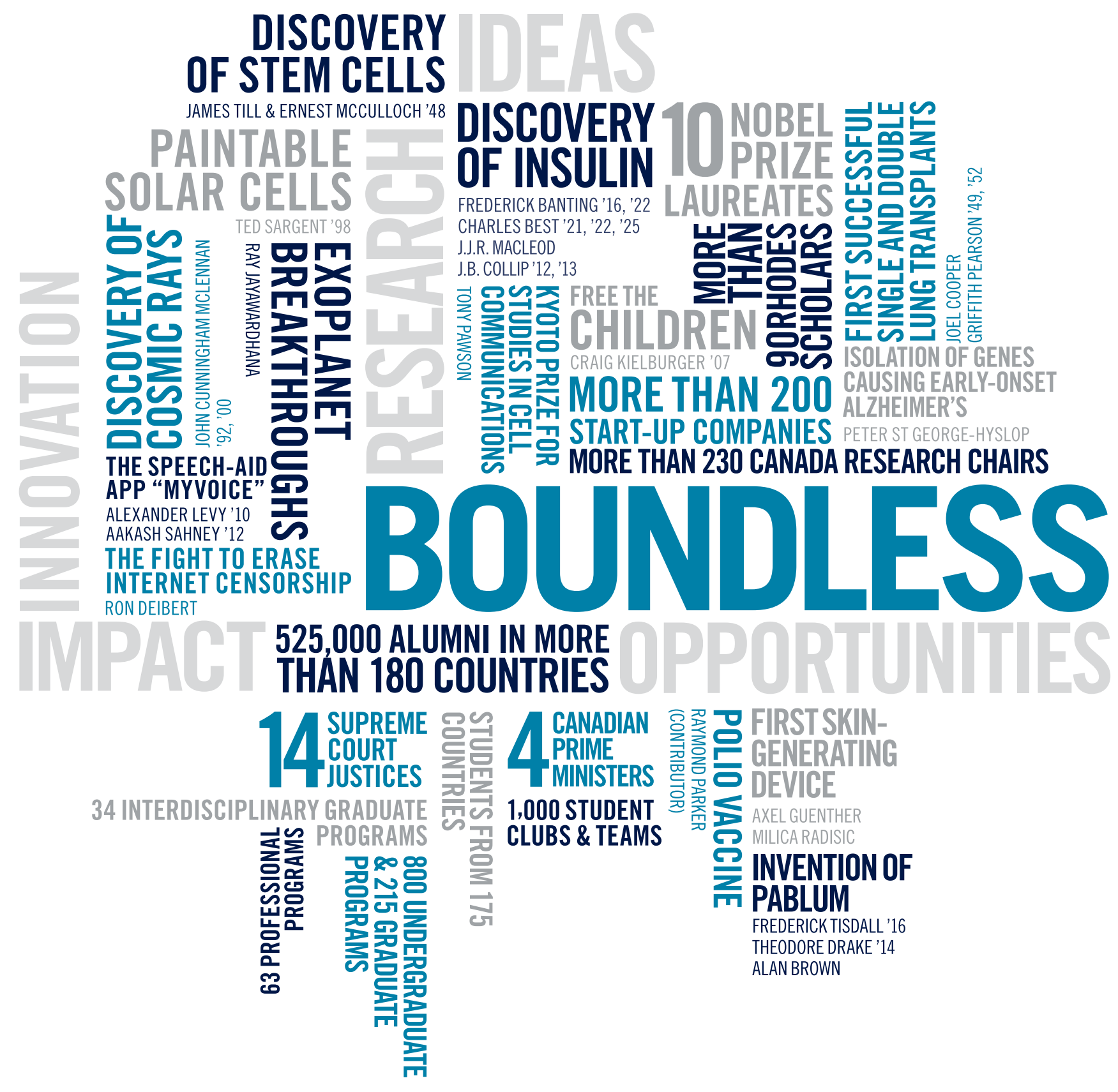

\section{A WORLD OF OPPORTUNITIES}

There is no better place to realize your potential than at the University of Toronto. Located at the heart of one of North America's top research and commercial hubs, the University of Toronto is a global leader in higher education and is consistently ranked as one of Canada's top 100 employers. With a large and diverse faculty there are also boundless opportunities for collaborative and multidisciplinary research. 


\section{Questions with}

the potential to

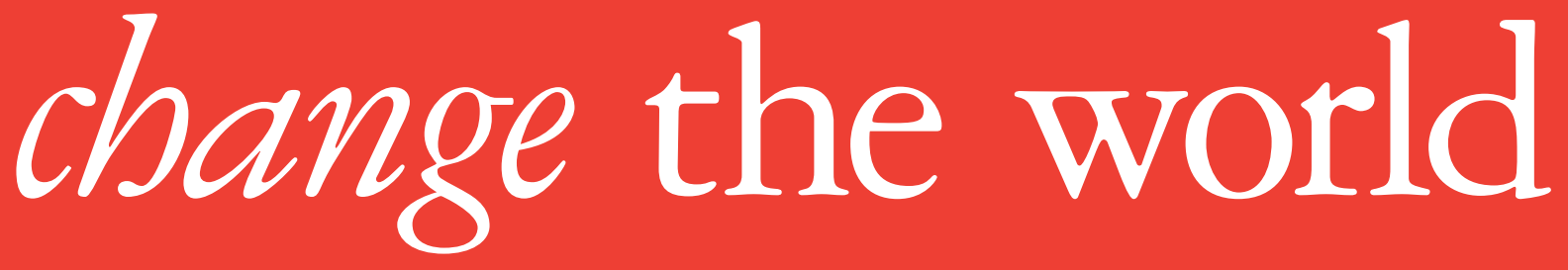

Profound questions focused on the sustainability of life on Earth, novel energy solutions, and the brain and consciousness are among seven short-listed concepts proceeding to Stage 2 of CIFAR's Global Call for Ideas.

The Canadian Institute for Advanced Research wishes to thank the global research community for their enthusiastic response to the Global Call for Ideas, launched April 2013. Over 800 researchers from 23 countries, on five continents submitted letters-of-intent to identify new research networks that could tackle complex, fundamental questions of importance to humanity.
In Stage 2, research teams come together to develop a full proposal. By June, 2014, CIFAR will announce a final selection of programs.

Established in 1982, CIFAR brings together some of the brightest minds in Canada and around the world to create knowledge that enriches human life and leads to a better future.

CIFAR GLOBAL CALL FOR IDEAS

See details of seven finalists at

cifar.ca/globalcall

\section{CIFAR}

CANADIAN

INSTITUTE

FOR

ADVANCED

RESEARCH 


\section{Université th} de Montréal

Department of Biochemistry and Molecular Medicine

Assistant or Associate Professor position in Bioinformatics

The Université de Montréal is one of the top three research universities in Canada. Applied and theoretical research in Bioinformatics, Medical Genomics and Human Genetics is a particular strength of our institution. Bioinformatics training programs are offered at the Bachelor, Master, and Ph.D. level in collaboration with the Department of Informatics and Operational Research and other Departments at the Université de Montréal.

The Department of Biochemistry and Molecular Medicine and the University-affiliated research institutes of the CHUM University Hospital, the IRCM (Clinical Research Institute of Montréal), the Montréal Heart Institute (MHI) and the Ste-Justine Children's Hospital solicit candidates who will be part of our institutional network in bioinformatics, genomics and genetics. We are seeking candidates with a strong research program in applied or theoretical bioinformatics, including, but not limited to, statistical bioinformatics, comparative and medical genomics, human genetics, molecular evolution, structure and function of RNAs and proteins, and metabolic and regulatory networks.

Candidates are expected to develop an internationally competitive research program, to interact with researchers in other disciplines within and beyond the Faculty of Medicine, to participate in teaching at the graduate and undergraduate levels and to contribute to functioning of the institution. Candidates will have a $\mathrm{Ph} . \mathrm{D}$. in Bioinformatics or in a related discipline, experience in research at the post-doctoral level and an excellent publication record. The language of teaching at the Université de Montréal is French; language training is offered to non-French speakers who will be required to be sufficiently proficient to teach in French after a period of three years.

The Université de Montréal offers competitive salary and benefits packages according to the collective agreement. The starting date is flexible and could be as early as July 2014. Applications will be accepted until November 1st 2013 and will be evaluated on an ongoing basis.

Interested candidates should send a letter of interest, complete $\mathrm{CV}$, research plan and the contact information for three referees, in electronic format, to the Search Committee:

Dr. Christian Baron, Chair

Department of Biochemistry and Molecular Medicine

Université de Montréal

C.P. 6128 succ. Centre-ville, Montréal (Québec) H3C 3J7, Canada

Email: christian.baron@umontreal.ca

The full text of the ad can be found at: http://www.biochimie.umontreal.ca/postes-stages/autres-postes/

NW241513R
UBC

CALL FOR NOMINATIONS

The Dr. Chew Wei MBBS [HK]

FRCOG [ENG] Memorial Prize

in Cancer Research

The University of British Columbia is currently seeking nominations for the 2014 Dr. Chew Wei MBBS [HK] FRCOG [ENG] Memorial Prize in Cancer Research, with a value of $C \$ 50,000$.

One Dr. Chew Wei MBBS [HK] FRCOG

[ENG] Memorial Prize in Cancer Research

will be awarded annually to a Canadian who has made outstanding contributions to the treatment, amelioration, or cure for cancer.

Among the criteria that will be considered is a distinguished record of translating scientific discoveries into clinical

applications, forging partnerships with

scientists and others to foster cancer

research or to implement discoveries, and cultivating future leaders in the field. The prize is awarded with the expectation that the recipient will continue to demonstrate excellence in their field of work and serve as leaders to other scientists in the field, sharing their insights for years to come.

Deadline for nominations:

December 13th, 2013 4:00pm PDT

For further information: www.med.ubc.ca/chewwei

\section{CHEMISTRY \& CHEMICAL BIOLOGY}

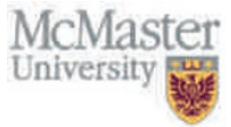

Tenure-Track Assistant Professor Position in Biointerfacial Chemistry

The Department of Chemistry \& Chemical Biology at McMaster University solicits applications to fill a tenure-track position at the rank of Assistant Professor in the area of biointerfacial chemistry, effective July 1, 2014. Applications are encouraged in all areas of chemistry of biointerfaces, including preparation, characterization, modeling or applications of biointerfaces. Scientists with research interests that have applications in the biosciences, environmental science and/or materials/nanoscience areas are encouraged to apply.

Our aim is to enhance interdisciplinary science at McMaster, a university with a longstanding history of collaborative research initiatives. In addition to having access to the equipment and facilities in this department and the newly established Biointerfaces Institute (http://biointerfaces.mcmaster.ca), the successful candidate will also have access to the facilities in the Brockhouse Institute for Materials Research, the Canadian Centre for Electron Microscopy, and the Centre for Microbial Chemical Biology. McMaster's new Biointerfaces Institute consists of several instrument suites for high throughput development and characterization of biomaterials and biointerfaces, including $850 \mathrm{MHz}$ solid-state biological NMR, imaging MALDI mass spectrometry, imaging XPS and automated materials synthesis and screening infrastructure, and supports current research themes in bioactive surfaces for sensing and separation, ophthalmic biomaterials, and fundamental studies of biointerface interactions. For additional information on the department, see: http://www.chemistry.mcmaster.ca.

Applicants should clearly demonstrate potential to develop a prominent, externally funded research program and a commitment to excellence in teaching at the graduate and undergraduate levels. Candidates must have a doctoral degree in chemistry or a closely related field, postdoctoral experience, and a promising record of research scholarship and productivity. Application materials must include a cover letter, curriculum vitae, a statement of teaching interests, and detailed descriptions of at least three research projects that exemplify the proposed research program. Please include a list of the major instrumentation and equipment necessary to pursue each project. Review of applications will begin by December 1,2013 and will continue until the position is filled. Please send these materials and arrange for three letters of recommendation to be sent to:

Dr. William J. Leigh, Chair

Department of Chemistry \& Chemical Biology,

McMaster University, 1280 Main Street West,

Hamilton, Ontario L8S 4MI CANADA

E-mail: chair@chemistrymcmaster.ca

All qualified candidates are encouraged to apply; however, Canadian citizens and permanent residents will be given priority. McMaster University is strongly committed to employment equity within its community, and to recruiting a diverse faculty and staff. The University encourages applications from all qualified candidates, including women, members of visible minorities, Aboriginal persons, members of sexual minorities, and persons with disabilities.

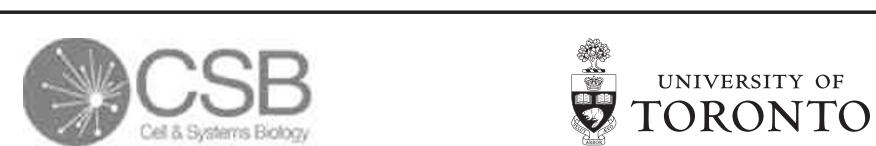

University of Toronto

25 Harbord Street, Toronto, ON Canada M5S 3G5

Fax (416) 978-8532 www.csb.utoronto.ca

\section{Cell Biology - University of Toronto}

The Department of Cell \& Systems Biology at the University of Toronto invites applications for a tenure-stream appointment at the rank of Assistant Professor beginning July 1, 2014.

We are seeking applicants with demonstrated excellence in research areas that will complement the strengths of the Department of Cell \& Systems Biology in genomics, plant and microbial biology, cell and developmental biology, or neurosciences. We will consider all outstanding applicants but are particularly interested in candidates that utilize advanced cell biological and imaging tools for the study of whole organism model systems. The University of Toronto and its affiliated institutions represent an outstanding world-class scientific environment with a highly interactive community of researchers.

The successful candidate should have substantial postdoctoral experience and will pursue a vigorous internationally-recognized research program. In addition, we expect a strong commitment to excellence in teaching and mentoring of undergraduate and graduate students. Salary will be commensurate with qualifications and experience.

All qualified candidates are invited to apply following the link below. Applications should include a cover letter, curriculum vitae, teaching dossier (including a statement of teaching philosophy), and a statement outlining current and future research interests. If you have questions about the position, please contact csbsearch@utoronto.ca. All application materials should be submitted online.

Please see submission guidelines at http://uoft.me/how-to-apply. Applications materials should be combined into a single PDF file of less than $5 \mathrm{Mb}$. Applicants should also ask at least three referees to send letters directly to the department via e-mail to csbsearch@utoronto.ca by the closing date, November 15, 2013.

For more information about the Department of Cell \& Systems Biology, please visit: http://www.csb.utoronto.ca/.

The University of Toronto is strongly committed to diversity within its community and especially welcomes applications from visible minority group members, women, Aboriginal persons, persons with disabilities, members of sexual minority groups, and others who may contribute to the further diversification of ideas. All qualified candidates are encouraged to apply; however, Canadians and permanent residents will be given priority. 